\title{
Numerical simulations of the reuse of piled raft foundations in clay
}

\author{
Brian Sheil ${ }^{1}$
}

Received: 5 April 2016/Accepted: 15 January 2017/Published online: 6 February 2017

(c) The Author(s) 2017. This article is published with open access at Springerlink.com

\begin{abstract}
The development and growth of urban environments in recent years is requiring geotechnical engineers to consider foundation reuse as a more sustainable solution to inner city redevelopment. Two main phenomena associated with foundation reuse have been reported in the literature, namely 'preloading effects' and 'ageing effects'. The aim of this paper is to investigate the relative merits of these effects on the reusability of both piled and unpiled raft foundations in clay. Finite element analysis, in conjunction with an isotropic elasto-viscoplastic soil model, is employed for this purpose. The study is presented in two phases: (1) evaluation of preloading effects only by using a very low creep coefficient and (2) evaluation of combined preloading and creep effects. The variables considered in the parametric study include the number of piles, pile spacing, pile length, and soil type. Results show that both unpiled and piled rafts can exhibit significant capacity and stiffness increases upon reloading even for moderate levels of preload. Moreover, these increases are strongly dependent on the piled raft load sharing where unpiled raft and free-standing pile group capacity gains serve as upper and lower bounds, respectively, for that of a piled raft. This study underlines foundations reuse as an effective and sustainable solution for inner city redevelopment.
\end{abstract}

Keywords Creep · Foundation reuse - Numerical · Preloading $\cdot$ Raft

Brian Sheil

brian.sheil@eng.ox.ac.uk

1 Department of Engineering Science, University of Oxford, Parks Road, Oxford OX1 3PJ, UK

\section{Introduction}

The development and growth of urban environments means taller buildings are becoming an increasingly common requirement due to the space restrictions associated with inner city redevelopment. This has led to geotechnical engineers moving away from shallow foundations to the point where most buildings now leave behind a set of deep foundations [10]. This poses geotechnical engineers with a new design challenge in inner city redevelopment-whether to avoid, remove or reuse the foundations of previous buildings.

The RuFUS (Reuse of Foundations for Urban Sites) project was undertaken in 2003 to encourage geotechnical engineers to consider foundation reuse towards more sustainable foundation design. Case histories of the successful reuse of existing pile foundations have been documented by Curtis [15] and Katzenbach et al. [27]. In addition, Butcher et al. [9] and König et al. [28] documented tests on existing piles 32 and 42 years after construction, respectively. Through comparisons to the existing records of pile tests undertaken during construction, both studies documented significant increases to the stiffness and capacity of the piles which were attributed to (1) preloading effects and (2) time (ageing) effects.

Experimental studies on foundation reuse are limited. Begaj and McNamara [2] utilised centrifuge modelling to investigate the influence of preloading on the load-displacement behaviour of single piles in Kaolin clay. These authors noted that the higher the level of preload, the higher the capacity of the pile upon reloading. More recently, Karlsrud [25] compiled a database of large-scale single pile load tests which were conducted at various soft soil test sites. In most cases, the author documented increases in pile capacity after preloading similar to that 
noted by Begaj and McNamara [2]. In addition to preloading effects, Karlsrud [25] noted that pile reloading capacity continued to increase long after full consolidation was estimated to finish; this was attributed to additional ageing set-up. Similarly, Lehane and Jardine [30], using large-scale tests on a shallow footing in Bothkennar clay, also noted that increases in undrained capacity and stiffness significantly exceeded that expected from comparable Modified Cam-Clay (MCC) predictions documented in the literature [60].

Full-scale tests on piled foundations are difficult and expensive to perform, and may not even be feasible if longterm conditions are to be examined. In light of this, numerical modelling has a particularly crucial role in the evaluation of foundation reuse as a feasible solution to inner city redevelopment. Cheng et al. [11] used 2-D finite element (FE) analysis, based on Biot's theory of consolidation, to examine the time-dependent behaviour of pileraft-soil interaction under vertical loads. Cui et al. [14] noted that the inclusion of the creep behaviour of clay is necessary for accurate simulation of the overall behaviour of a piled raft, which was determined using an elasto-viscoplastic constitutive model in conjunction with coupledconsolidation FE analysis. Similarly, Bodas Freitas et al. [5], using an overstress-based elasto-viscoplastic model, reported significant increases in the bearing capacity of shallow footings on soft clay due to both preloading and time effects. More recently, Elsawy and Ismail [17] employed the soft soil (SS) model to study the influence of time effects on the bearing capacity of shallow circular footings using 2-D FE modelling. These authors noted that the bearing capacity increased significantly with pore pressure dissipation (creep effects were not taken into account).

The research presented in this paper makes use of FE modelling to investigate the influence of preloading and creep effects on the reuse of both piled and unpiled raft foundations in clay. An elasto-viscoplastic model in conjunction with the finite element software package PLAXIS 3-D Foundation has been adopted for this purpose. The approach followed in this study is as follows: (1) the unpiled/piled raft is loaded to failure in order to determine its 'virgin' ultimate capacity and load-displacement stiffness; (2) the unpiled/piled raft systems are preloaded to a certain percentage of their virgin ultimate capacity where the load is subsequently maintained for a determined period of time; (3) unloading and subsequent reloading of the foundation to determine its new ultimate capacity and stiffness. The variables considered in the parametric study include the number of piles, pile spacing, pile length and soil type.

\section{Modelling time-dependent behaviour of clays}

There are two processes associated with the settlement behaviour of clays, namely primary consolidation and secondary consolidation. Primary consolidation is compression due to changes in effective stress which is now very well understood. By contrast, secondary consolidation is compression at constant effective stress, the underlying mechanisms of which remain very much open to question and the subject of numerous recent investigations. Two main hypotheses for the cause of the delayed compression associated with secondary consolidation have featured in the literature: (1) sliding of microparticles relative to each other inducing changes in microstresses and vice versa [54]; (2) drainage from micropores after macropores have experienced dissipation of pore pressure $[3,6,13,47]$. The latter theory is based on evidence that two different scales of porosity exist in many natural geomaterials, relating to (1) intra-aggregate micropores and (2) inter-aggregate macropores, e.g. [16].

Although modelling of the complex drainage processes of double-porosity media is not currently feasible in routine finite element analyses of soil-structure interaction, constitutive modelling of secondary consolidation has evolved significantly. One of the earliest creep laws developed was that by Buisman [8] for one-dimensional compression of clays. Subsequent advances were made by Bjerrum [4], Sing and Mitchell [48], Garlanger [18], Leroueil et al. [32], Mesri and Castro [37], and Yin and Graham [56]. More theoretical formulations were later documented by Sekiguchi [43], Adachi and Oka [1], and Borja and Kavazanjian [7]. Highly advanced constitutive models have recently been developed to capture various soil characteristics including soil destructuration, anisotropy (due to deposition history) and cyclic loading $[19,20,24,26,31,34,35,41,49$, $55,57,59,61]$. This is not intended to be an exhaustive list, however, and more in-depth discussion on this topic is available in Liingaard et al. [33].

The soft soil creep (SSC) model was chosen for this study as a compromise between robustness of predictions and model simplicity (and therefore simplicity of parameter determination). The fundamentals associated with this model are based on the work of Buisman [8], Šuklje [50], Bjerrum [4] and Garlanger [18]. This model accounts for some of the basic mechanical features of soils such as stress-dependent stiffness, MohrCoulomb failure criterion, distinction between primary loading and unloading-reloading, time-dependent compression behaviour and associated flow rule for plastic strains. It can be considered as an extension to the soft soil (SS) model in that while the yield surface retains a similar shape, it can expand due to creep. 
Therefore, while the SS model predicts purely elastic behaviour within the yield surface, there is no purely elastic region when using the SSC model as plastic strains due to creep is permitted.

Of the more advanced constitutive models documented in the literature, the anisotropic creep model (ACM) [31], the non-associated creep model for structured anisotropic clay (n-SAC) [19], and the structured anisotropic creep model (S-CLAY1S) [26] are quite popular. Differences between these models and the adopted SSC model include relating the creep term to the plastic multiplier (n-SAC and S-CLAY1S models) rather than the volumetric creep strain rate (SSC and ACM models). As an isotropic model, SSC employs a non-rotated elliptical yield surface which contrasts with the rotated ellipses of the anisotropic models. The n-SAC and S-CLAY1S models also account for soil destructuration which can therefore capture soil post-peak strain-softening behaviour. Gustafsson and Tiang [21] appraised predictions of long-term settlement determined by the SSC, ACM and n-SAC models through comparisons to measurements in the laboratory. These authors noted that the SSC model provided comparable predictions while also reducing the complexity of the numerical analyses. The SSC model is therefore suitable for large parametric analyses while also providing sufficiently accurate predictions of the time dependency of soil behaviour.

\section{Constitutive model and parameters}

\subsection{Details of the adopted constitutive model}

In the SSC model, the elastic strain rate depends on the rate of increase in mean effective stress, whereas the viscoplastic strain rate depends on the current state of effective stress and strain relative to a reference creep rate (defined at a reference intrinsic time corresponding to a reference preconsolidation pressure on the reference isotache).

Similar to the approaches documented by Yin et al. [58] and Bodas Freitas et al. [5], the SSC model decomposes the total strains, $\varepsilon$, into elastic strains, $\varepsilon^{e}$, and viscoplastic strains, $\varepsilon^{c}$ :

$\varepsilon=\varepsilon^{e}+\varepsilon^{c}$

The viscoplastic portion, $\varepsilon^{c}$, can be separated further into strains occurring during pore pressure dissipation and after primary settlement has ended. In this model, the 3-D stress measure $p^{e q}$ is considered as a constant on ellipses in $p^{\prime}-q$ space which is derived from the mean effective stress, $p^{\prime}$, and the deviator stress, $q$, as follows: $p^{e q}=p^{\prime}+\frac{q^{2}}{M^{2} p^{\prime}}$

$M=\frac{6 \sin \varphi_{c s}}{3-\sin \varphi_{c s}}$

where $\varphi_{c s}$ is the critical state friction angle. The volumetric creep strain, $\dot{\varepsilon}_{v}^{c}$, is then obtained from the following expression:

$-\dot{\varepsilon}_{v}^{c}=\frac{\mu^{*}}{\tau}\left(\frac{p^{e q}}{p_{p}^{e q}}\right)^{\frac{\lambda^{*}-k^{*}}{\mu^{*}}}$

$p_{p}^{e q}=p_{p 0}^{e q} \exp \left(\frac{-\varepsilon_{v}^{c}}{\lambda^{*}-\kappa^{*}}\right)$

where $p_{p}^{e q}$ is a generalised preconsolidation pressure, $\tau$ is the reference time for the model, $\lambda^{*}$ is the modified compression index, $\kappa^{*}$ is the modified swelling index, $\mu^{*}$ is the modified creep index and the subscript ' 0 ' is used to represent initial conditions, i.e. at time, $t=0$ and $\varepsilon_{v}^{c}=0$.

Therefore, the volume change occurring during a creep period, $t$, can be obtained using the following expression:

$\Delta \varepsilon_{v}^{c}=\mu^{*} \ln \left(1+\frac{t}{\tau}\left(\frac{p^{e q}}{p_{p 0}^{e q}}\right)^{\frac{\mu^{*}-k^{*}}{\mu^{*}}}\right)$

It is clear from Eq. 6 that the creep ratio, $\left(\lambda^{*}-\kappa^{*}\right) / \mu^{*}$, determines the change in creep rate with time, whereas $\mu^{*}$ determines the creep rate at the reference time ( $\tau=1$ day for the SSC model). Further details of this model are available elsewhere in the literature $[52,53]$.

\subsection{Soft clay parameter selection}

The soft soil parameters adopted herein are presented in Table 1 and are representative of the heavily researched Bothkennar carse clay test site in Scotland. These parameters are largely based on data documented by Nash et al. [38, 39]. The validation of the SSC model for the Bothkennar test site has been documented elsewhere $[44,45]$. The predicted load-displacement behaviour of two pad footings is shown in Fig. 1 and compared to measured data of two pad footing field tests in Bothkennar clay, namely Pad A and Pad B, documented by Jardine et al. [23]. The stepped curve associated with the experimental data indicates the loading stages adopted in the experimental programme. While this was not modelled explicitly in the present study, the total loading was applied over the same time period to replicate as closely as possible the experimental conditions. In both cases, it can be seen that the SSC predictions show very good agreement to the measured data. In addition, predictions of the time settlement behaviour of Pad B have also been compared to the 
Table 1 Bothkennar (soft clay) Soft Soil Creep model parameters

\begin{tabular}{llll}
\hline Parameter & Crust & Upper Carse clay & Lower Carse clay \\
\hline Depth $(\mathrm{m})$ & $0-1.5$ & $1.5-2.5$ & $2.5-14.5$ \\
Unit weight $\gamma\left(\mathrm{kN} / \mathrm{m}^{3}\right)$ & 18.0 & 16.5 & 16.5 \\
Overconsolidation ratio, OCR & - & - & 1.5 \\
Preoverburden pressure, POP $(\mathrm{kPa})$ & 15 & 15 & - \\
Friction angle, $\varphi^{\prime}\left(^{\circ}\right)$ & 34 & 34 & 34 \\
Dilatancy angle, $\Psi\left(^{\circ}\right)$ & 0 & 0 & 0 \\
Cohesion, $c^{\prime}(\mathrm{kPa})$ & 1.0 & 1.0 & 1.0 \\
Coefficient of lateral earth pressure at rest, $\mathrm{K}_{0}$ & 1.5 & 0.049 & 0.75 \\
Modified compression index, $\lambda^{*}$ & 0.015 & $6.0 \times 10^{-3}$ & 0.16 \\
Modified swelling index, $\kappa^{*}$ & $2.0 \times 10^{-3}$ & $2.0 \times 10^{-3}$ & $8.1 \times 10^{-3}$ \\
Modified creep index, $\mu^{*}$ & $6.0 \times 10^{-4}$ & 0.2 & $4 \times 10^{-3}$ \\
Poisson's ratio for unloading-reloading, $v_{u r}$ & 0.2 & $1 \times 10^{-4}$ & 0.2 \\
Horiz. coefficient of permeability, $k_{x}(\mathrm{~m} / \mathrm{day})$ & $1 \times 10^{-4}$ & $6.9 \times 10^{-5}$ & $1 \times 10^{-4}$ \\
Vert. coefficient of permeability, $k_{y}(\mathrm{~m} /$ day $)$ & $6.9 \times 10^{-5}$ & 0.6 & $6.9 \times 10^{-5}$ \\
Interface strength reduction factor, $R_{\text {inter }}$ & 0.8 & 0.6 \\
\hline
\end{tabular}

(a)

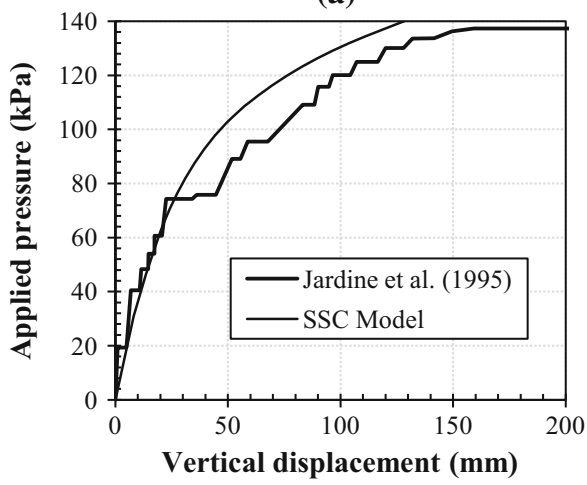

(b)

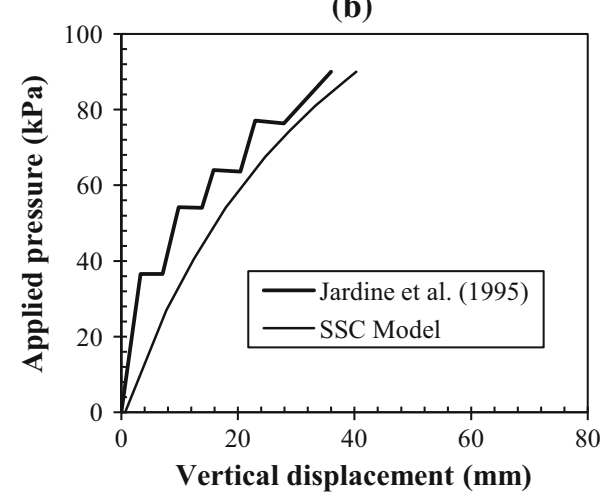

Fig. 1 Comparison of measured load-displacement response with predictions determined using the SSC model for a Pad A and $\mathbf{b}$ Pad B

measured response in Fig. 2. Again, it is clear that the SSC model predicts the response very well. The role of various pile/raft/soil parameters on the influence of preloading and creep effects is difficult to discern if a complex soil profile

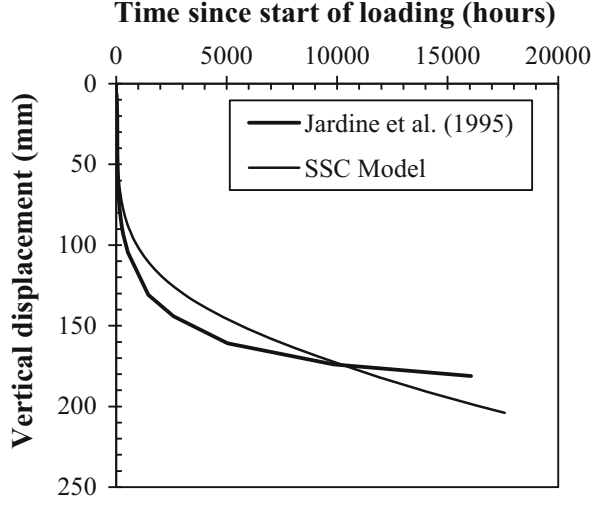

Fig. 2 Comparison of SSC predictions and measured time settlement response of $\mathrm{Pad} \mathrm{B}$

is adopted. Therefore, a simplified uniform profile of lower Carse clay has been adopted in the subsequent analyses of the soft clay profile to provide a systematic examination of the role of preloading and creep effects on foundation reuse.

\subsection{Stiff clay parameter selection}

Results determined using a layered stiff clay profile have also been included for comparative purposes. This more realistic profile has been adopted to contrast with the uniform soft clay profile. The stiff clay SSC parameters used in this study are based on the behaviour of Boston Blue Clay (BBC) and are listed in Table 2. The adopted values were chosen based on the values documented by Neher et al. [40] in conjunction with the detailed testing 
Table 2 Boston Blue Clay (stiff clay) Soft Soil Creep model parameters

\begin{tabular}{|c|c|c|c|c|c|c|}
\hline Parameter & $A$ & $B$ & $C$ & $D$ & $E$ & $F$ \\
\hline Depth (m) & $0-3$ & $3-9$ & $9-15$ & $15-18$ & $18-27$ & $27-50$ \\
\hline Overconsolidation ratio, OCR & 8.34 & 3.8 & 2 & 1.3 & 1.21 & 1.14 \\
\hline Modified compression index, $\lambda^{*}$ & 0.052 & 0.065 & 0.087 & 0.13 & 0.196 & 0.152 \\
\hline Modified swelling index, $\kappa^{*}$ & $1.3 \times 10^{-2}$ & $1.6 \times 10^{-2}$ & $2.18 \times 10^{-2}$ & $3.26 \times 10^{-2}$ & $4.89 \times 10^{-2}$ & $3.81 \times 10^{-2}$ \\
\hline Modified creep index, $\mu^{*}$ & $1.49 \times 10^{-3}$ & $1.86 \times 10^{-3}$ & $2.49 \times 10^{-3}$ & $3.7 \times 10^{-3}$ & $5.6 \times 10^{-3}$ & $4.35 \times 10^{-3}$ \\
\hline Horiz. coefficient of permeability, $k_{x}$ (m/day) & $2.8 \times 10^{-4}$ & $1.8 \times 10^{-4}$ & $8.1 \times 10^{-5}$ & $9.2 \times 10^{-5}$ & $1.0 \times 10^{-4}$ & $7.6 \times 10^{-5}$ \\
\hline Vert. coefficient of permeability, $k_{y}$ (m/day) & $1.4 \times 10^{-4}$ & $9.0 \times 10^{-5}$ & $5.4 \times 10^{-5}$ & $6.1 \times 10^{-5}$ & $6.7 \times 10^{-5}$ & $5.0 \times 10^{-5}$ \\
\hline Sat weight density $\gamma_{\text {sat }}\left(\mathrm{kN} / \mathrm{m}^{3}\right)$ & \multicolumn{6}{|c|}{16.5} \\
\hline Unsat. weight density $\gamma_{\text {unsat }}\left(\mathrm{kN} / \mathrm{m}^{3}\right)$ & \multicolumn{6}{|c|}{16.5} \\
\hline Friction angle, $\varphi^{\prime}\left({ }^{\circ}\right)$ & \multicolumn{6}{|c|}{33.4} \\
\hline Dilatancy angle, $\Psi\left(^{\circ}\right)$ & \multicolumn{6}{|c|}{0} \\
\hline Cohesion, $c^{\prime}(\mathrm{kPa})$ & \multicolumn{6}{|c|}{1} \\
\hline Coefficient of lateral earth pressure at rest, $\mathrm{K}_{0}$ & \multicolumn{6}{|c|}{0.5} \\
\hline Poisson's ratio for unloading-reloading, $v_{u r}$ & \multicolumn{6}{|c|}{0.2} \\
\hline Interface strength reduction factor, $R_{\text {inter }}$ & \multicolumn{6}{|c|}{0.6} \\
\hline
\end{tabular}

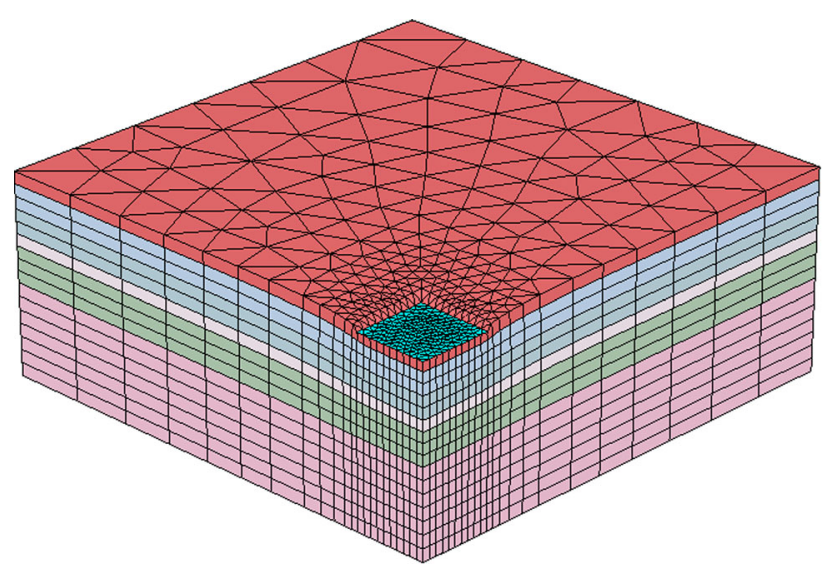

Fig. 3 Illustration of a typical (deformed) FE mesh for an unpiled raft (quarter symmetry)

programme documented by Ladd et al. [29]. Neher et al. [40] noted that for overconsolidated soils the SSC model gives similar predictions to its predecessor, the soft soil (SS) model. The ability of the SS model to realistically capture the behaviour of stiff overconsolidated soils has been documented by a number of investigators in the literature, e.g. $[40,51]$. A value of 0.6 has been chosen for the interface strength reduction factor, $R_{\text {inter }}$, for BBC [36].

\section{Details of the FE modelling}

\subsection{System geometries and boundary conditions}

An example of a typical FE mesh used in this study is illustrated in Fig. 3 for an unpiled raft on the stiff clay

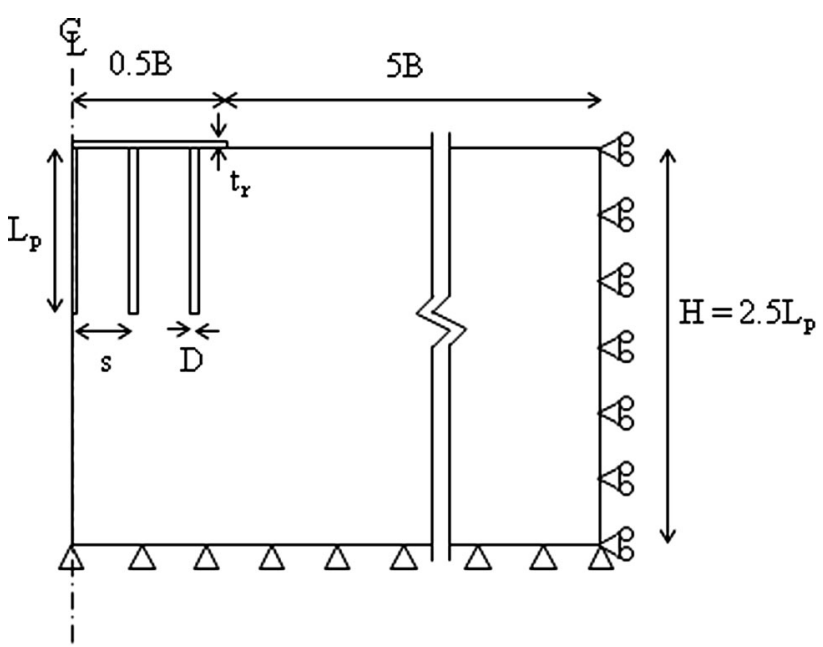

Fig. 4 Illustration of FE model parameters and boundaries (quarter symmetry)

profile. Fifteen-node wedge elements were used in this study comprising 6-node triangular elements in the horizontal direction and 8-node quadrilateral elements in the vertical direction. Symmetry was exploited to reduce the number of elements used in the mesh (which varied up to a maximum of $\sim 110,000$ elements) and associated computational time. The depth below ground level to the bottom mesh boundary, $H$, was chosen as $2.5 L_{p}$ so that the lower mesh extremity had no effect on the FE output, where $L_{p}$ is the pile length (see Fig. 4). Likewise, the lateral (roller) boundaries of the FE model for each analysis were located at a distance $5 B$ from the edge of the footing where $B$ is the footing width. 
(a)

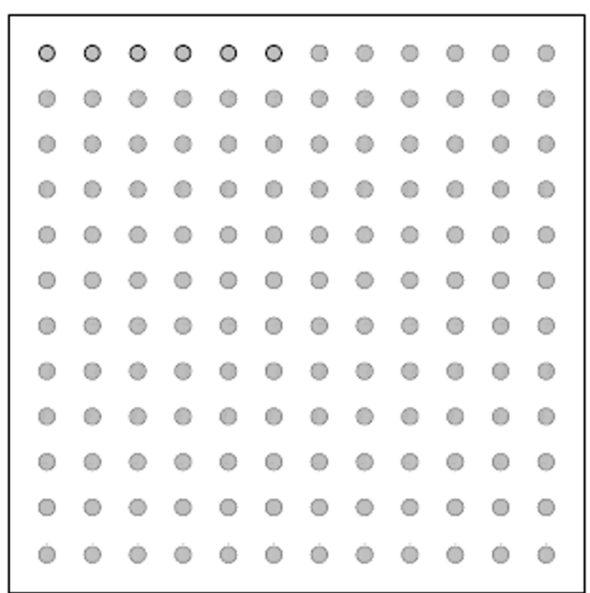

(b)

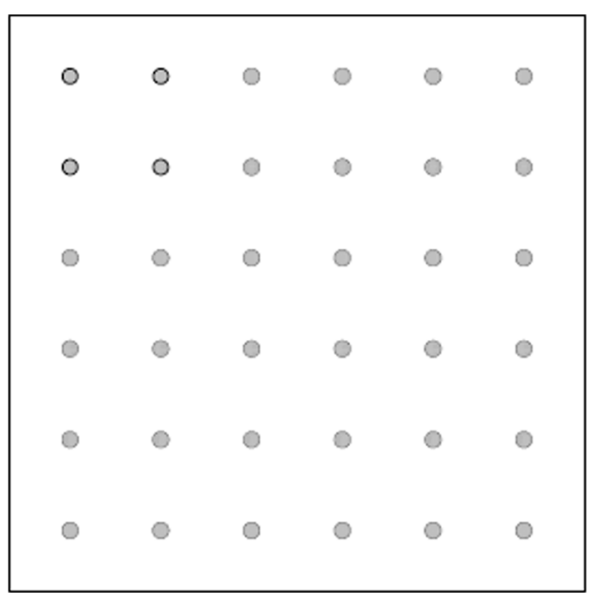

Fig. 5 Plan view of a group A: $N=144, s=3 \mathrm{~m}$ and b group B: $N=36, s=6 \mathrm{~m}$

Table 3 Piled raft parameters considered in this study

\begin{tabular}{ll}
\hline Parameter & Values \\
\hline Number of piles, $N$ & 0 (unpiled), 36, 144 \\
Pile spacing, $s(\mathrm{~m})$ & 3,6 \\
Pile length, $L_{p}(\mathrm{~m})$ & 20,40 \\
\hline
\end{tabular}

The base-case scenario for this study comprised a square raft with a width, $B$, of $38 \mathrm{~m}$ and piles uniformly spaced over the entire raft area as shown in Fig. 5. Two common pile spacings, $3 \mathrm{~m}$ and $6 \mathrm{~m}$, were adopted. A pile diameter, $D$, of $1.0 \mathrm{~m}$ was maintained throughout the parametric analyses. A default pile length of $L_{p}=20 \mathrm{~m}$ was selected with a limited number of analyses using $L_{p}=40 \mathrm{~m}$ conducted for comparison. The pile-raft area ratio, $r_{a}$, is a composite term which accounts for variations in both the number of piles and pile spacing and is defined here as the total plan area of the piles as a percentage of the plan area of the raft; values of $7.8 \%$ and $2.0 \%$ were calculated for group A and group B respectively. The variations in the parameters considered in this study are presented in Table 3.

\subsection{Analysis stages}

The stages used in the analysis of a piled raft (similar stages were adopted for an unpiled raft) are defined as follows:

1. Inclusion of interface elements in the soil model to allow for pile-soil slip.

2. Generation of the initial soil stresses using the soil unit weight and lateral earth pressure at rest.

3. 'Wished-in-place' installation of the concrete piles reflected by changing appropriate elements to a linear elastic material with a Young's modulus of $30 \mathrm{GPa}$ and a Poisson's ratio, $v$, of 0.15 . A neutral stress regime after pile installation (and subsequent consolidation) is widely accepted for bored piles and has recently been shown to be a reasonable approximation for driven piles in lightly overconsolidated clays [46].

4. Installation of the raft along the top of the pile heads which is in contact with the ground surface. The raft was modelled as 6-node triangular plate elements with the same properties of the concrete pile.

5. Pile group loading by placing a compressive uniformly distributed load on the top surface of the raft. Coupled consolidation analyses revealed that negligible pore pressures were present at the end of loading over a time step of 6 months, representing realistic construction time of a small/medium building [5]. In the light of this, drained conditions have been assumed henceforth; this is consistent with the modelling of piled rafts in clayey soils documented elsewhere, e.g. Cho et al. [12], Reul and Randolph [42]. An added advantage is that creep effects are readily identified under drained conditions, thus eliminating the need to differentiate consolidation effects [44].

In each of the subsequent analyses, both unpiled and piled raft capacity was defined as the load required to generate an average raft displacement of $0.1 B$ [12].

\subsection{Post-analysis}

In this study, the 'total' settlements of the foundation were calculated as the average settlements from the FE output according to Reul and Randolph [42]:

$\delta=\left(2 \delta_{\text {centre }}+\delta_{\text {corner }}\right) / 3$

where $\delta_{\text {centre }}$ and $\delta_{\text {corner }}$ are the settlements at the centre and corner of the raft, respectively. The total differential settlement is calculated as follows: 
$\Delta=\left|\delta_{\text {centre }}-\delta_{\text {corner }}\right|$

The raft-soil stiffness, $K_{r s}$, is defined by Horikoshi and Randolph [22] as:

$K_{r s}=5.57 \frac{E_{r}}{E_{s}} \frac{1-v_{s}^{2}}{1-v_{r}^{2}}\left(\frac{B}{L}\right)^{0.5}\left(\frac{t_{r}}{L}\right)^{3}$

where $E_{r}$ and $E_{s}$ are the Young's modulus of the raft and soil, respectively; $v_{r}$ and $v_{s}$ are the Poisson's ratio of the raft and soil, respectively; $B$ and $L$ are the breadth and length of the raft, respectively; and $t_{r}$ is the thickness of the raft. An equivalent elastic Young's modulus (corresponding to a load factor of 0.75) was chosen for the value of $E_{s}$ in Eq. 9 according to the approach recommended by Reul and Randolph [42]. A raft thickness, $t_{r}$, of $1 \mathrm{~m}$ was chosen to give realistic values of $K_{r s}$ encountered in practice [42]; a value of 1.1 and 0.44 was ultimately calculated for the soft clay and stiff clay profiles, respectively.

In addition, the load sharing within the piled rafts is characterised by the piled raft coefficient, defined as:

$\alpha_{p r}=\frac{\sum R_{\text {pile }, i}}{R_{\text {total }}}$

where $R_{\mathrm{pile}, i}$ is the resistance contributed by pile $i$ and $R_{\text {total }}$ is the total load applied to the piled raft. Thus, a value of $\alpha_{p r}$ of 0 and 1 represents an unpiled raft and free-standing pile group, respectively.

\section{Preloading effects}

\subsection{Unpiled rafts}

For the purpose of initially investigating preloading effects only, a very low creep coefficient was employed, thus limiting the influence of creep on the foundation reloading behaviour. In this study, the behaviour of an equivalent unpiled raft after preloading serves as a reference for the behaviour of piled rafts (shown in Fig. 5) in the subsequent sections. Therefore, various aspects of the behaviour of unpiled rafts are examined first.

In these analyses, increases in raft capacity and stiffness due to preloading effects are only attained when the apparent preconsolidation pressure of the soil is exceeded. The development of volumetric and shear hardening (i.e. expansion of the normal consolidation surface) beneath the unpiled raft at various stages of preloading is presented in Figs. 6 and 7 for the soft clay and stiff clay profiles, respectively. In these figures, the level of preload is expressed as a percentage of the 'virgin' ultimate capacity. Both figures show that an increase in preload induces a corresponding increase in both the shear and volumetric hardening. Surprisingly, a $25 \%$ preload is sufficient to induce volumetric hardening beneath the raft for both soil profiles. It can also be seen that the volumetric hardening extends to greater depths for the stiff clay profiles. This is because the stiff clay analyses require much higher applied loads compared to the soft clay analyses to obtain an equivalent raft displacement which in turn causes volumetric hardening to occur at greater depths.

Figure 8 plots the variation in $E / E_{0}$ with depth beneath the centre of the raft after various degrees of preloading where $E$ is the current Young's modulus of the soil and $E_{0}$ is the far-field (undisturbed) Young's modulus. Larger increases in $E / E_{0}$ are achieved for the soft clay profile due to the lower OCR values nearer the surface compared to the stiff clay case.

By way of example, the normalised load-displacement behaviour of an unpiled raft which has experienced preloads of $50 \%, 75 \%$ and $100 \%$ has been compared to the initial 'virgin' load-displacement behaviour in Fig. 9 for the stiff clay profile. In this plot, $Q$ is the applied load, $Q_{i}$ is the virgin raft capacity, and $\delta$ is calculated using Eq. 7. In general, preloading causes an increase in (1) the capacity and (2) the stiffness of the load-displacement

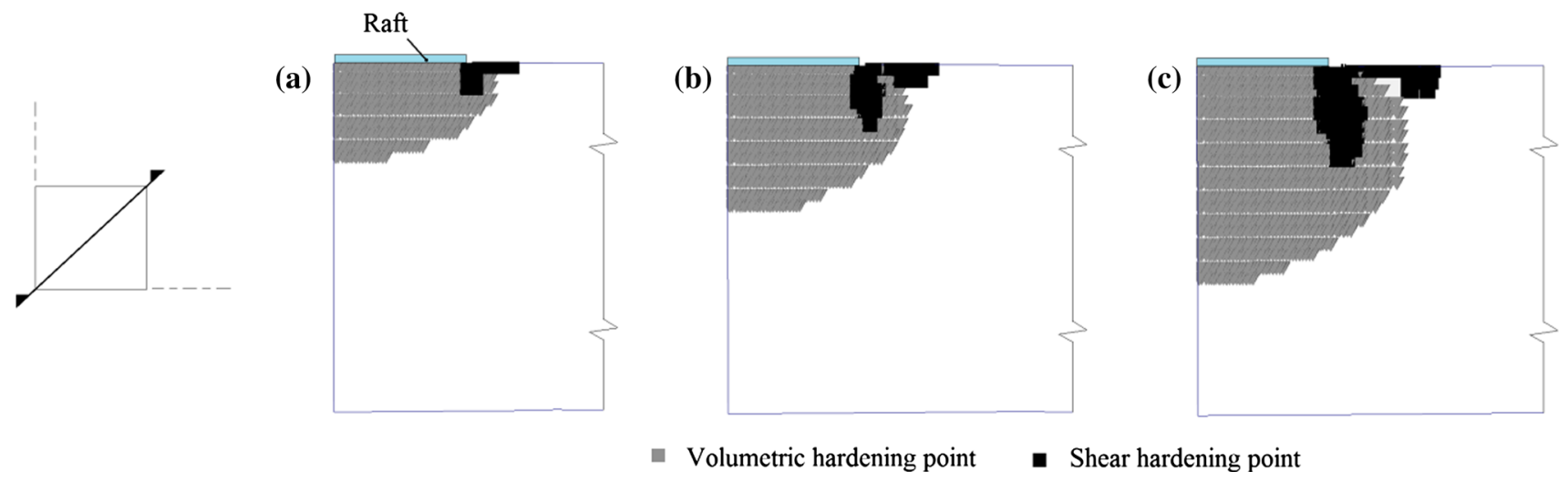

Fig. 6 Hardening points under unpiled raft for a 25\%, b $50 \%$ and c $100 \%$ preload on soft clay 


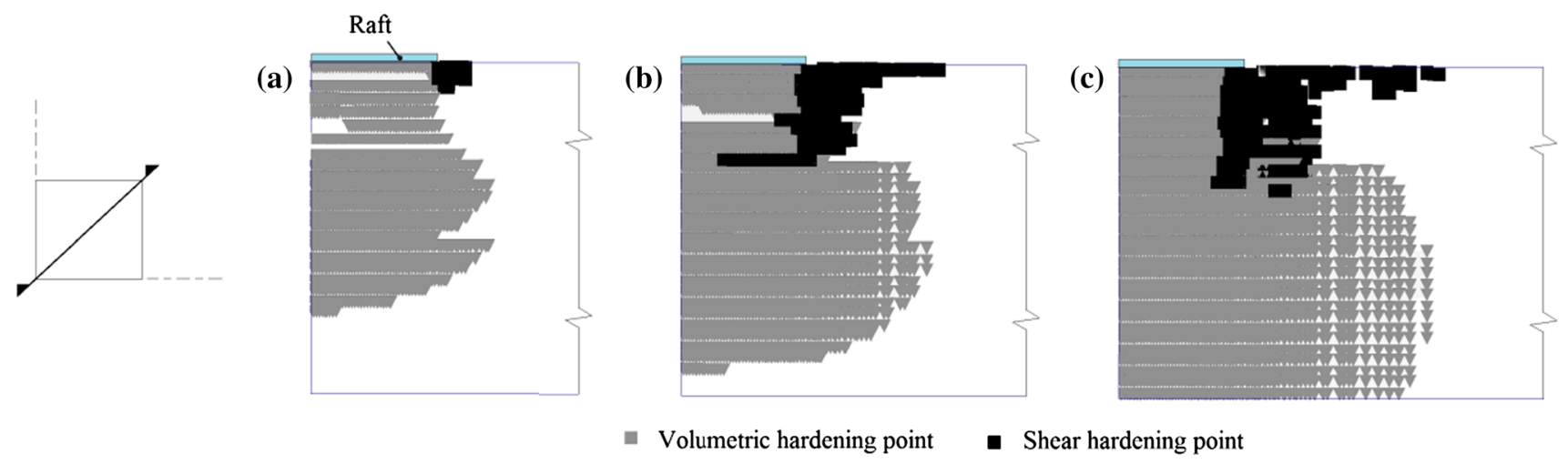

Fig. 7 Hardening points under unpiled raft for a 25\%, b 50\% and c $100 \%$ preload on stiff clay

behaviour of the raft. For load levels of $Q / Q_{i}<30 \%$, all four load cases exhibit similar load-displacement stiffness. This is to be expected since at low load levels the soil beneath the raft remains overconsolidated even for the virgin loading case (see Table 2), and therefore, the stiffness will be similar. A preload as low as $50 \%$ is sufficient to induce stiffening of the raft behaviour which is to be expected based on the results presented in Figs. 6, 7 and 8.

In Fig. 10, the ratio of the unpiled raft capacity after preloading, $Q$, to the virgin raft capacity, $Q_{i}$, is plotted against the level of preload for both soil profiles. It can be seen that predictions of $Q / Q_{i}$ for the soft clay profile are much larger than the corresponding stiff clay case. This can be explained by differences in the OCR profile where significantly greater hardening will occur for the soft clay case. The magnitudes of the capacity increases are surprising and indicate that an unpiled raft loaded to failure can experience an increase in capacity of up to $100 \%$ upon reloading. Predictions documented by Zdravkovic et al. [60] pertaining to a shallow $10 \mathrm{~m} \times 10 \mathrm{~m}$ footing on soft normally consolidated clay have also been superimposed on the graph; these were determined using a form of the Modified Cam-Clay model in a coupled consolidation FE analysis. Direct comparisons to these results are not strictly justified as those analyses involved undrained loading and subsequent pore pressure dissipation. Nevertheless, the linear trends of $Q / Q_{i}$ versus $\%$ preload presented here are consistent with those results.

For the purpose of comparing load-displacement stiffness, the author has chosen to compare raft settlements corresponding to the same load level. A load factor (LF) of 0.75 on virgin capacity (illustrated in Fig. 9) was selected for these comparisons. In Fig. 11a, the ratio of the raft displacement upon reloading, $\delta$, to the virgin raft displacement, $\delta_{i}$ (at the same load level) is plotted against percentage preload. It is again apparent that preloading has a significantly greater influence on the reloading settlements in the case of the soft clay profile compared to the stiff clay profile. Preloading to failure can reduce settlements by up to $90 \%$ upon reloading. The ratio of differential settlements, $\Delta / \Delta_{i}$, are plotted against preload level in Fig. 11b, where no clear trends are evident. This is partly due to the smaller magnitude of the differential settlements compared to the total settlements $(\Delta / \delta \leq 0.05$ typically). These fluctuating trends were consistent throughout the analyses, and therefore, variations in differential settlements have not been presented henceforth.

\subsection{Piled rafts}

In Fig. 12, the influence of pile-raft area ratio, $r_{a}$, on the behaviour of a piled raft after preloading is considered through comparisons between group A and group B predictions (illustrations provided in Fig. 5). Results for an equivalent unpiled raft are also superimposed on these plots for comparative purposes. The variation in $Q / Q_{i}$ with the level of preload is first considered in Fig. 12a. For the uniform soft clay case, the behaviour of an equivalent unpiled raft serves as an upper bound to the reloading behaviour of piled rafts. An increase in the value of $r_{a}$ corresponds to a further reduction in the capacity gains upon reloading. Piles transfer the applied load through skin friction, thereby reducing the extent of volumetric hardening. By contrast, capacity gains exhibited by group B are slightly greater than that of an unpiled raft for the stiff clay profile. The increased reloading capacity of group B is attributable to two competing mechanisms: (1) increased pile-soil interaction which was seen to reduce capacity gain for the uniform soft clay profile; (2) transfer of the applied loads to depths where the OCR is now significantly lower compared to that near the surface (see Table 1).

The findings of Fig. 12a are largely replicated in Fig. $12 \mathrm{~b}$ for $\delta / \delta_{i}$. In particular, it is apparent that upper and lower bound reloading stiffness predictions correspond to the unpiled raft and group A, respectively.

The influence of $L_{p}$ on $Q / Q_{i}$ and $\delta / \delta_{i}$ is examined in Fig. 13a, b, respectively, using pile lengths of $20 \mathrm{~m}$ and $40 \mathrm{~m}$. Figure 13a shows that an increase in $L_{p}$ 
(a)

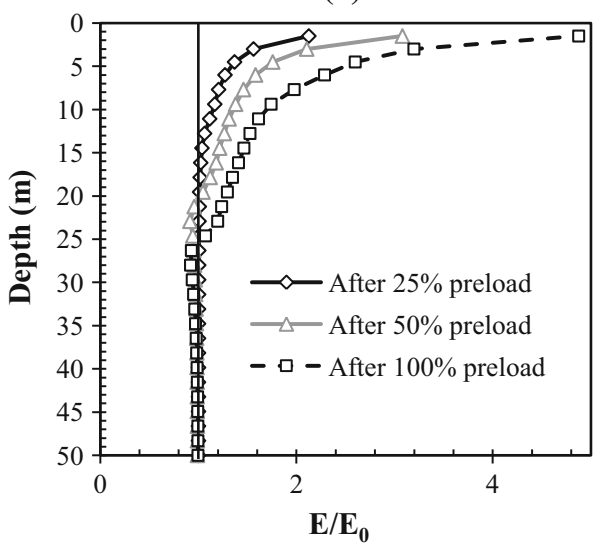

(b)

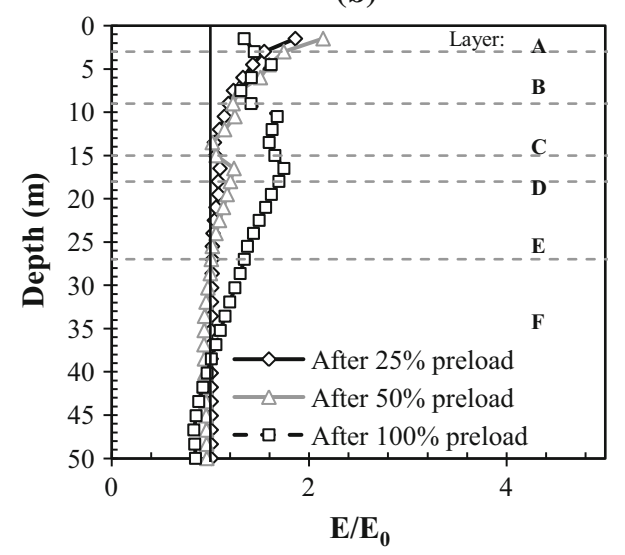

Fig. 8 Variation in $E / E_{0}$ with depth under centre of raft after unloading for $\mathbf{a}$ soft clay and $\mathbf{b}$ stiff clay profiles

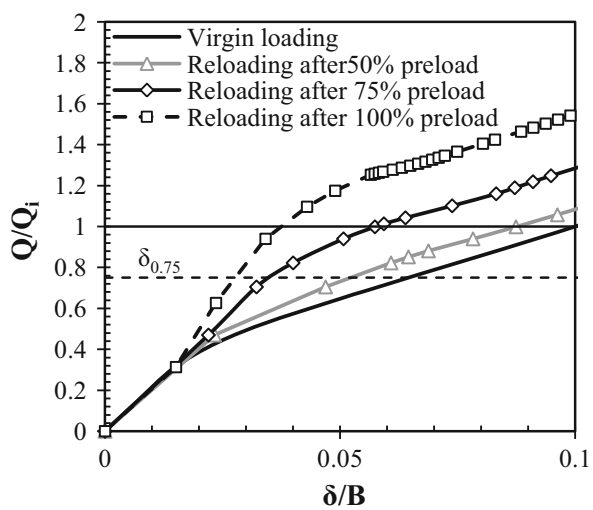

Fig. 9 Illustration of load-displacement behaviour after preloading of unpiled raft in stiff clay

corresponds to further reductions in $Q / Q_{i}$ lending further support that increased pile-soil interaction reduces capacity gains. These findings are again applicable to Fig. $13 \mathrm{~b}$ for $\delta / \delta_{i}$ where the unpiled raft case remains an upper bound estimation for the behaviour of a piled raft.

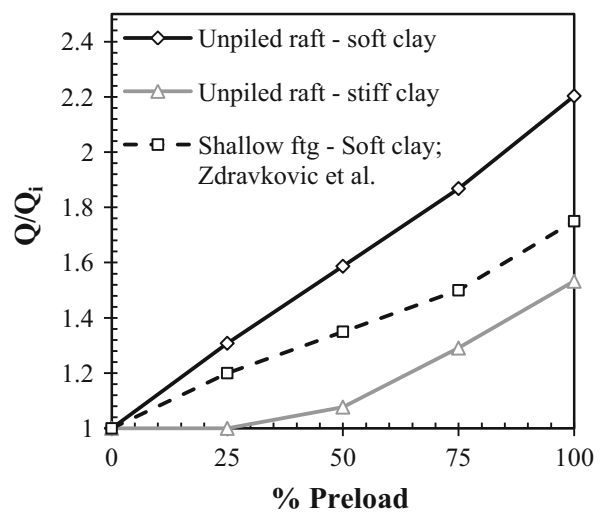

Fig. 10 Influence of preloading on $Q / Q_{i}$ for an unpiled raft

(a)

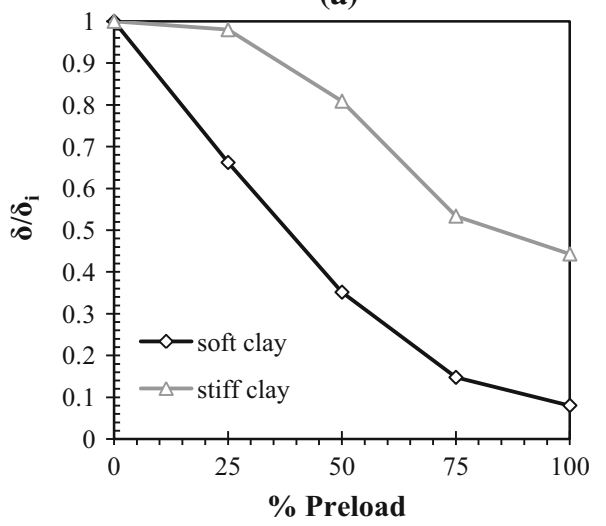

(b)

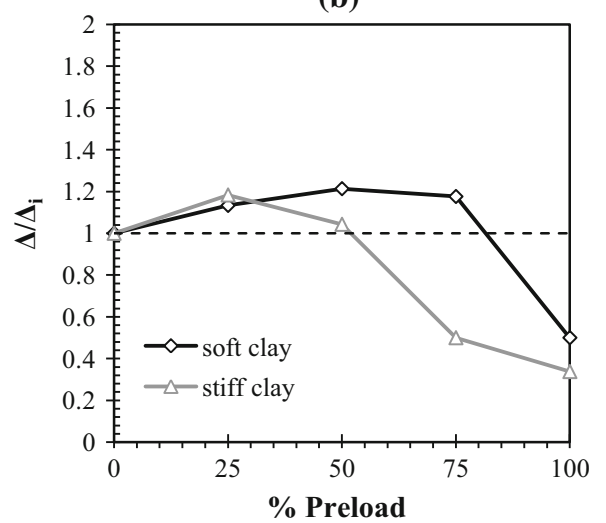

Fig. 11 Influence of preloading on $\mathbf{a} \delta / \delta_{i}$ and $\mathbf{b} \Delta / \Delta_{i}$ for an unpiled raft

\section{Combined preloading and creep effects}

\subsection{Unpiled rafts}

In this section, the influence of creep effects on raft reloading is examined by maintaining the applied load, described in step (v) of Sect. 4.2, over a period of $t$ years before reloading; $t$ is varied between 0.01 and 
(a)

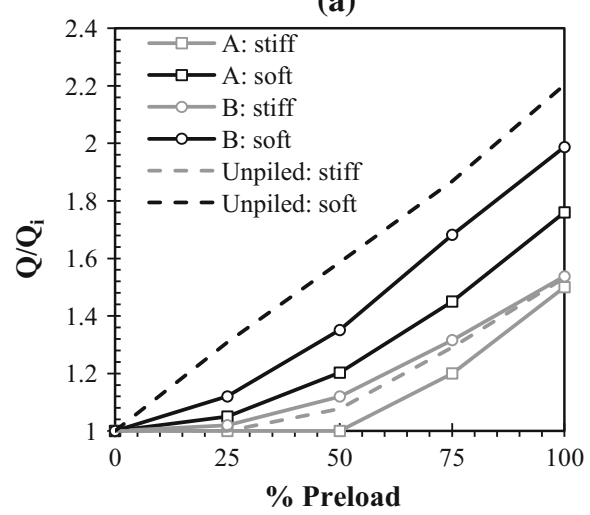

(b)

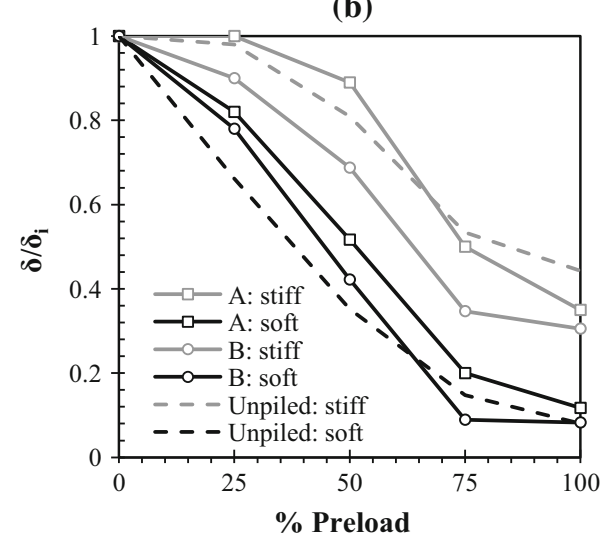

Fig. 12 Influence of pile-raft area ratio on increases in a $Q / Q_{i}$ and b $\delta_{\mathrm{p}} / \delta_{i}$ due to preloading; $L_{p}=20 \mathrm{~m}$

100 years in the subsequent analyses. The change in volumetric strain with maintained load time, $t$, predicted by the SSC model is described by Eq. 6. In turn, this volumetric strain has the effect of increasing the value of $p_{p}^{e q}$ (see Eq. 5) which leads to a larger OCR upon unloading of the raft, thereby increasing soil strength and stiffness.

The influence of creep effects on $Q / Q_{i}$ and $\delta / \delta_{i}$ of an unpiled raft founded on both soil profiles is illustrated in Fig. 14a, b, respectively, for preloads of 50, 75 and $100 \%$ of the virgin ultimate capacity. Figure 14 a shows that $Q / Q_{i}$ varies approximately linearly with the logarithm of time where both profiles exhibit similar increases in $Q / Q_{i}$. This is not surprising since, after loading is applied, the soil is brought to a near normally consolidated state in both cases. These results support the findings of the RuFUS programme where appreciable increases to foundation capacity were noted over time. Creep effects also appear to cause a reduction in $\delta / \delta_{i}$ where predictions for both profiles are relatively similar (see Fig. 14b). Interestingly, the influence of the level of preload appears to be relatively insignificant if the loading duration is $>1$ year. (a)

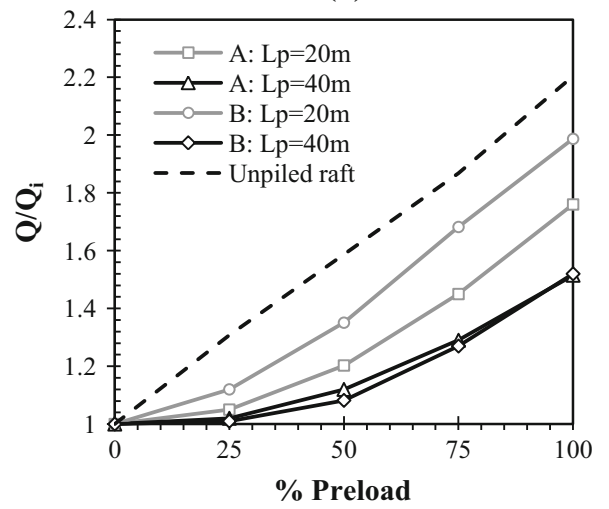

(b)

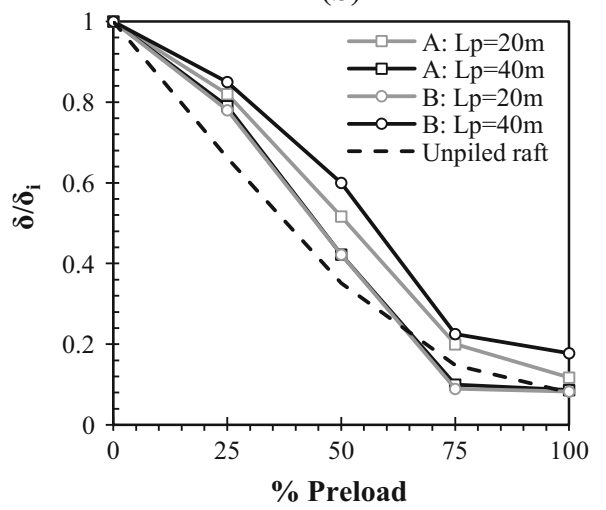

Fig. 13 Influence of pile length on increases in a $Q / Q_{i}$ and $\mathbf{b} \delta / \delta_{i}$ due to preloading; soft clay profile

\subsection{Piled rafts}

For the purpose of comparing the influence of creep effects on piled rafts, a preload of $75 \%$ has been adopted. This level of preload is consistent with a partial factor of safety of 1.35 on unfavourable dead loads as defined in Eurocode 7. Therefore, it is assumed that the foundation will experience its maximum design load at some stage over its lifetime. Corresponding predictions determined for an unpiled raft have again been superimposed on the plots for comparison. The variation in $Q / Q_{i}$ and $\delta / \delta_{i}$ with maintained load time is presented in Fig. 15a, b, respectively. While it is clear that creep effects also increase $Q / Q_{i}$ for piled rafts, in most cases the increases are slightly less than those corresponding to an unpiled raft. It can also be seen that group A, in particular, experiences the smallest increases to $Q / Q_{i}$ for both soil profiles due to the greater number of piles. Interestingly, the additional creep effects appear to have less of an influence on $\delta / \delta_{i}$ (Fig. 15b) compared to Fig. 15a where group A shows negligible improvement for both soil profiles.

In general, it is clear that unpiled and piled rafts do not exhibit the same increases in $Q / Q_{i}$ with time. As 
(a)

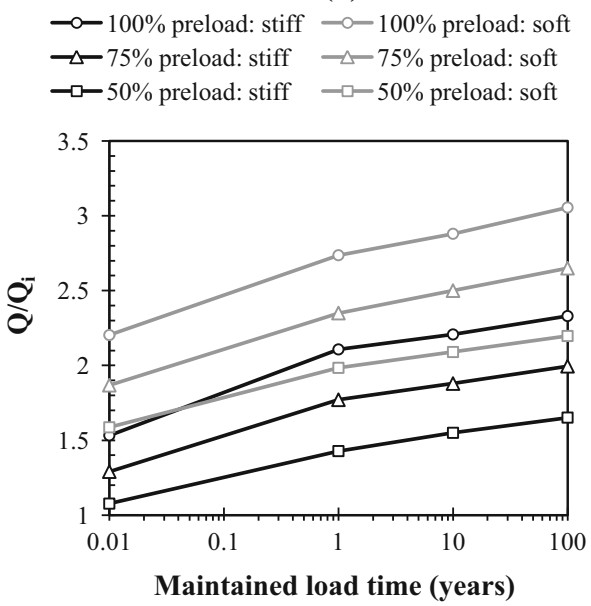

(b)

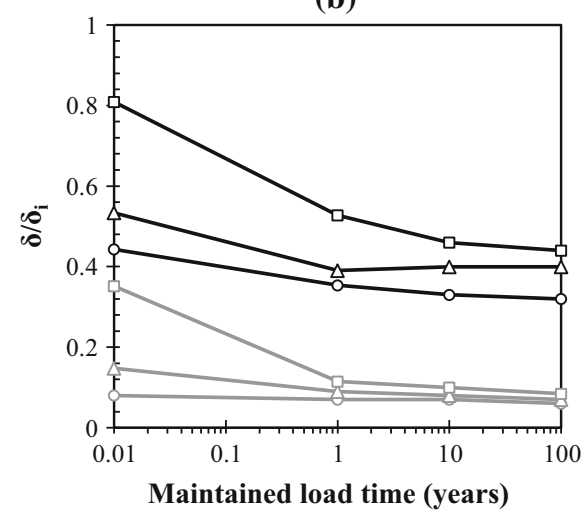

Fig. 14 Influence of maintained load on a $Q / Q_{i}$ and $\mathbf{b} \delta / \delta_{i}$ for an unpiled raft

mentioned, increased pile-soil interaction reduces the extent of volumetric hardening beneath the raft compared to an equivalent unpiled raft. Therefore, during the maintained loading, the soil beneath the unpiled raft has a lower OCR. From Eq. 4, this corresponds to a greater creep rate, thus explaining the discrepancies in $Q / Q_{i}$ with time.

\section{Role of load sharing on foundation reuse}

Based on the results presented in the previous sections, an increase in pile-soil interaction appears to reduce the extent of both capacity and stiffness gain on reloading. To this end, the influence of the piled raft load sharing during virgin loading, $\alpha_{\mathrm{pr}, \mathrm{i}}$, on $Q / Q_{i}$ is explored for the soft clay (Fig. 16a) and stiff clay (Fig. 16b) cases for a 75\% preload. From Fig. 16a, there appears to be a linear relationship between $\alpha_{\mathrm{pr}, \mathrm{i}}$ and $Q / Q_{i}$ for preloading effects only (i.e. no creep). Moreover, predictions for the cases with additional creep effects also indicate a linear relationship although further work is clearly necessary to confirm. Based on this (a)

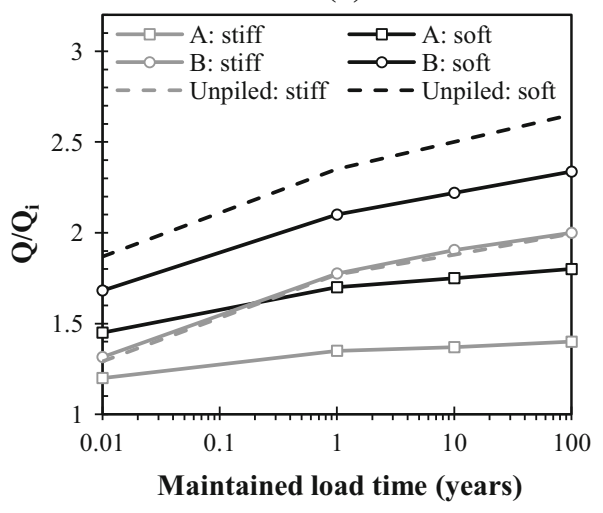

(b)

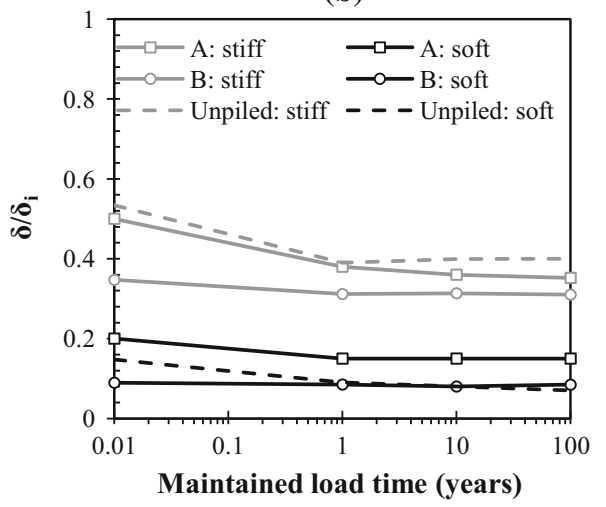

Fig. 15 Influence of maintained load on a $Q / Q_{i}$ and b $\delta / \delta_{i}$; $L_{p}=20 \mathrm{~m}, 75 \%$ preload

research unpiled raft $\left(\alpha_{p r, i}=0\right)$ and free-standing pile group $\left(\alpha_{p r, i}=1\right)$ capacity gains appear to serve as upper and lower bounds, respectively, for that of a piled raft.

While Fig. 16a indicated a strong linear trend between load sharing and capacity gain, the results of the stiff clay (and arguably more realistic) profile do not exhibit linear relationships (see Fig. 16b). It is interesting to note that additional creep effects appear to have a negligible influence for values of $\alpha_{p r, i} \geq 0.4$ and therefore should not be relied upon in design. In the light of these results, it is clear that although capacity gain is strongly linked to piled raft load sharing, the stratification of real soil profiles renders these trends limited to uniform (ideal) soil profiles.

\section{Conclusions}

A 3-D finite element study of the influence of preloading and creep effects on the reloading behaviour of unpiled and piled raft foundations in clay has been presented using an elastoviscoplastic constitutive model. A total of 90 systems were analysed in the course of this study using two contrasting soil profiles. In general, preloading was shown to significantly 
(a)

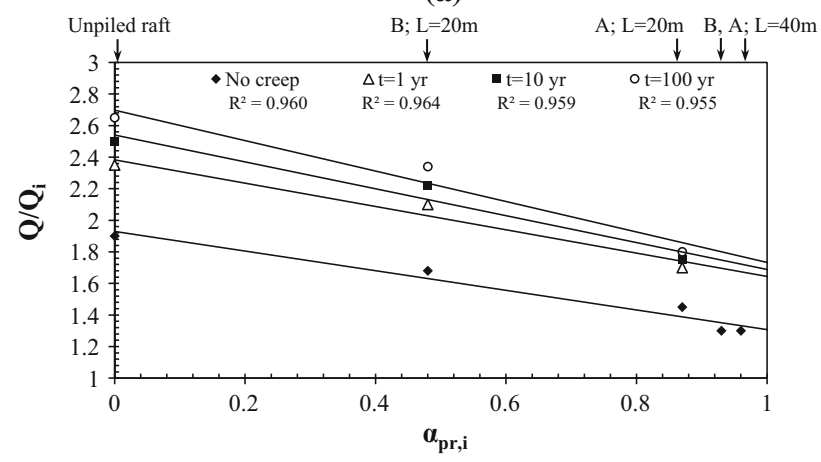

(b)

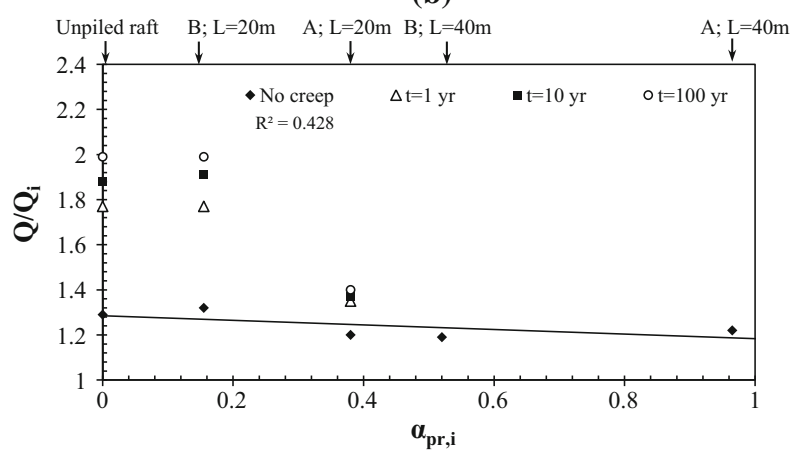

Fig. 16 Influence of $\alpha_{p r}$ on $Q / Q_{i}$ for $\mathbf{a}$ soft clay and $\mathbf{b}$ stiff clay case; $75 \%$ preload

improve both the capacity and stiffness of piled and unpiled raft foundations on clay. In most cases, preloading had a greater influence on the reloading behaviour of unpiled rafts compared to piled rafts. This was attributed to the piles shedding load through pile shaft resistance which reduced the volumetric hardening beneath the raft. An increase in the length of the piles led to further reductions in both capacity and stiffness gain. When additional creep effects were introduced into the analyses, reloading capacities and stiffness exhibited further increases where the unpiled rafts again showed the greatest improvements. The capacity gain experienced by an unpiled and piled raft foundation was also shown to be linearly dependent on the piled raft load sharing in a uniform soil deposit. This highlights the possibility of developing numerical trends to aid the prediction of foundation reuse in practice. This study underlines foundation reuse as an effective and sustainable solution for inner city redevelopment and forms an important frame of reference for future studies.

Open Access This article is distributed under the terms of the Creative Commons Attribution 4.0 International License (http:// creativecommons.org/licenses/by/4.0/), which permits unrestricted use, distribution, and reproduction in any medium, provided you give appropriate credit to the original author(s) and the source, provide a link to the Creative Commons license, and indicate if changes were made.

\section{References}

1. Adachi T, Oka F (1982) Constitutive equation for normally consolidated clays based on elastoviscoplasticity. Soils Found 22:57-70

2. Begaj L, McNamara AM (2011) Centrifuge model testing for pile foundation reuse. Int J Phys Model Geotech 11(4):166-177

3. Bennett KC, Berla WD, Nix WD, Borja RI (2015) Instrumented nanoindentation and 3D mechanistic modeling of a shale at multiple scales. Acta Geotech 10:1-14

4. Bjerrum L (1967) Engineering geology of Norwegian normallyconsolidated marine clays as related to the settlements of buildings. Géotechnique 17(2):83-119

5. Bodas Freitas TM, Potts DM, Zdravkovic L (2012) The effect of creep on the short-term bearing capacity of pre-loaded footings. Comput Geotech 42:99-108. doi:10.1016/j.compgeo.2011.11.009

6. Borja RI, Choo J (2016) Cam-Clay plasticity, Part VIII: a constitutive framework for porous materials with evolving internal structure. Comput Methods Appl Mech Eng 309:653-679

7. Borja RI, Kavazanjian E (1985) A constitutive model for the stress-strain-time behaviour of 'wet' clays. Géotechnique 35:283-298

8. Buisman K (1936) Results of long duration settlement tests. Paper presented at the proceedings of the 1st international conference on soil mechanics and foundation engineering, Cambridge, Massachusetts, USA

9. Butcher AP, Skinner HD, Powell JJM (2006) Stonebridge parka demolition case study. Paper presented at the proceedings of the international conference on reuse of foundations for urban sites (RuFUS), Watford

10. Chapman T, Marsh B, Foster A (2001) Foundations for the future. Proc ICE-Geotech Eng 144:36-41

11. Cheng ZH, Ling DS, Chen YM (2004) Time effects on piled raft foundation under vertical loading. China Civ Eng J 37(2):73-77

12. Cho J, Lee JH, Jeong S, Lee J (2012) The settlement behaviour of piled raft in clay soils. Ocean Eng 53:153-163

13. Cosenza P, Korošak D (2014) Secondary consolidation of clay as an anomalous diffusion process. Int J Numer Anal Meth Geomech 38:1231-1246

14. Cui C, Luan M, Zhao Y (2009) Time-dependent behavior of piled-raft on soil foundation with reference to creep and consolidation. Electron J Geotech Eng 14:1-14

15. Curtis DC (2006) Risk assessment for increasing loads on existing piles at Manchester Airport. Paper presented at the proceedings of the international conference on reuse of foundations for urban sites (RuFUS), Watford

16. Delage P, Lefebvre G (1984) Study of the structure of sensitive Champlain clay and its evolution during consolidation. Can Geotech J 21:21-35

17. Elsawy MBD, Hafez Ismail KM (2013) Influence of aging on bearing capacity of circular footing resting on soft soil. HBRC J 9(3):256-262. doi:10.1016/j.hbrcj.2013.05.010

18. Garlanger JE (1972) The consolidation of soils exhibiting creep under constant effective stress. Géotechnique 22:71-78

19. Grimstad G, Degado SA (2010) A non-associated creep model for structured anisotropic clay (n-sac). In: Benz T, Nordal S (eds) Numerical methods in geotechnical engineering. CRC Press, Florida

20. Grimstad G, Degado SA, Nordal S, Karstunen M (2010) Modelling creep and rate effects in structured anisotropic soft clays. Acta Geotech 5:69-81

21. Gustafsson P, Tian T (2011) Numerical study of different creep models used for soft soils. Master of Science thesis, Chalmers University of Technology 
22. Horikoshi K, Randolph MF (1997) On the definition of raft-soil stiffness ratio. Géotechnique 47(5):1055-1061

23. Jardine RJ, Lehane BM, Smith PR, Gildea PA (1995) Vertical loading experiments on rigid pad foundations at Bothkennar. Géotechnique 45(4):573-597

24. Jiang J, Ling HI, Kaliakin VN, Zeng X, Hung C (2016) Evaluation of an anisotropic elastoplastic-viscoplastic bounding surface model for clays. Acta Geotech. doi:10.1007/s11440-0160471-7

25. Karlsrud K (2012) Prediction of load-displacement behaviour and capacity of axially loaded piles in clay based on analyses and interpretation of pile load test results. Ph.D. thesis, Ph.D. Thesis, Norwegian University of Science and Technology, Trondheim, Norway

26. Karstunen M, Krenn H, Wheeler SJ, Koskinen M, Zentar R (2005) Effect of anisotropy and destructuration on the behaviour of Murro test embankment. Int J Geomech 5(2):87-97

27. Katzenbach R, Ramm H, Werner A (2006) Reuse of foundations in the reconstruction of the Hessian Parliament complex-a case study. Paper presented at the proceedings of the international conference on reuse of foundations for urban sites (RuFUS), Watford

28. König F, Grabe J, Franke J, Woldt J (2006) Load bearing behaviour of an existing pile foundation and changes with time. Paper presented at the proceedings of the international conference on reuse of foundations for urban sites (RuFUS), Watford

29. Ladd CC, Young GA, Kraemer SR, Burke DM (1999) Engineering properties of Boston Blue Clay from special testing program. Paper presented at the proceedings of ASCE geocongress

30. Lehane BM, Jardine RJ (2003) Effects of long-term pre-loading on the performance of a footing on clay. Géotechnique 53(8):689-695

31. Leoni M, Karstunen M, Vermeer PA (2008) Anisotropic creep model for soft soils. Géotechnique 58(3):215-226

32. Leroueil S, Kabbaj M, Tavenas F, Bouchard R (1985) Stressstrain-strain rate relation for the compressibility of sensitive natural clays. Géotechnique 35:159-180

33. Liingaard M, Augustesen A, Lade PV (2004) Characterization of models for time-dependent behaviour of soils. Int $\mathrm{J}$ Geomech 4(3):157-177

34. Ma G, Zhou W, Ng T-T, Cheng Y-G, Chang X-L (2015) Microscopic modeling of the creep behaviour of rockfills with a delayed particle breakage model. Acta Geotech 10:481-496

35. Maranha JR, Pereira C, Vieira A (2016) A viscoplastic subloading soil model for rete-dependent cyclic anisotropic structured behaviour. Int $\mathrm{J}$ Numer Anal Meth Geomech 40:1531-1555

36. McCabe BA, Sheil BB (2015) Pile group settlement estimation: suitability of nonlinear interaction factors. ASCE Int J Geomech 15(3):04014056

37. Mesri G, Castro A (1987) $C_{\alpha} / C_{c}$ concept and $K_{0}$ during secondary compression. J Geotech Eng 113(3):230-247

38. Nash DFT, Powell JJM, Lloyd IM (1992) Initial investigations of the soft clay test site at Bothkennar. Géotechnique 42(2):163-181

39. Nash DFT, Sills GC, Davison LR (1992) One-dimensional consolidation testing of soft clay from Bothkennar. Géotechnique 42(2):241-256

40. Neher HP, Wehnert M, Bonnier PG (2001) An evaluation of soft soil models based on trial embankments. In: al. De (ed) Proceedings of 10th international conference on computer methods and advances in geomechanics, Tucson. A.A. Balkelma, pp 373-378

41. Raude S, Laigle F, Giot R, Fernandes R (2016) A unified thermoplastic/viscoplastic constitutive model for geomaterials. Acta Geotech 11:849-869
42. Reul O, Randolph MF (2004) Design strategies for piled rafts subjected to nonuniform vertical loading. J Geotech Geoenviron Eng 130(1):1-13

43. Sekiguchi H (1977) Rheological characteristics of clays. Paper presented at the proceedings of the 9th international conference for soil mechanics and foundation engineering, Tokyo, Japan

44. Sexton BG (2014) Numerical modelling of the improvement to secondary settlement offered by granular columns. National University of Ireland, Galway

45. Sexton BG, McCabe BA (2013) Numerical modelling of the improvements to primary and creep settlements offered by granular columns. Acta Geotech 8(4):447-464

46. Sheil BB, McCabe BA, Hunt CE, Pestana JM (2015) A practical approach for the consideration of single pile and pile group installation effects in clay: numerical modelling. J Geo-Eng Sci $2(3,4): 119-142$

47. Shi XS, Herle I (2014) Numerical simulation of lumpy soils using a hypoplastic model. Acta Geotech. doi:10.1007/s11440-0160447-7

48. Singh A, Mitchell JK (1968) General stress-strain-time function for soils. J Soil Mech Found Div ASCE 94(1):21-46

49. Sivasithamparam N, Castro J (2016) An anisotropic elastoplastic model for soft clats based on logarithmic contractancy. Int $\mathrm{J}$ Numer Anal Meth Geomech 40:596-621

50. Suklje L (1957) The analysis of the consolidation process by isotaches method. Paper presented at the proceedings of 4th international conference on soil mechanics and foundation engineering, London, UK

51. Sururak C (2010) Geotechnicalm aspects of the bangkok MRT blue line project. PhD Thesis, Griffith University

52. Vermeer PA, Neher HP (1999) A soft soil model that accounts for creep. In: Brinkgreve RBJ (ed) Beyond 2000 in computational geotechnics. Ten years of PLAXIS International, Amsterdam. A.A. Balkema, pp 18-20

53. Vermeer PA, Stolle DFE, Bonnier PG (1998) From the classical theory of secondary compression to modern creep analysis. Paper presented at the 9th international conference on computer methods advanced geomechanics, Wuhan, China

54. Wahls HE (1962) Analysis of primary and secondary consolidation. ASCE J Soil Mech Found Div 88(SM6):207-231

55. Wheeler SJ, Naatanen A, Karstunen M, Lojander M (2003) An anisotropic elastoplastic model for soft clays. Can Geotech J 40(2):403-418

56. Yin J-H, Graham J (1989) Viscous-elastic-plastic modeling of one-dimensional time-dependent behaviour of clays. Can Geotech J 26:199-209

57. Yin ZY, Karstunen M (2008) Influence of anisotropy, Destructuration and viscosity on the behaviour of an embankment on soft clay. Paper presented at the proceedings of the 12th international conference of international association for computer methods and advances in geomechanics (IACMAG), Goa, India, 1-6 October

58. Yin ZY, Chang CS, Karstunen M, Hicher PY (2010) An anisotropic elastic-viscoplastic model for soft clays. Int J Solids Struct 47(5):665-677

59. Yin ZY, Karstunen M, Chang CS, Koskinen M, Lojander M (2011) Modelling time-dependent behaviour of soft sensitive clay. J Geotech Geoenviron Eng 137(11):1103-1113

60. Zdravkovic L, Potts DM, Jackson C (2003) Numerical study of the effect of preloading on undrained bearing capacity. Int $\mathrm{J}$ Geomech 3(1): 1-10

61. Zhu Q-Y, Yin Z-Y, Hicher P-Y, Shen S-L (2016) Nonlinearity of one-dimensional creep characteristics of soft clays. Acta Geotech 11:887-900 